\title{
Blink reflexes in severe traumatic coma
}

\author{
R. B U O N A G U I D I, B. R OS I, F. S A R T U C C I, \\ A N D V. R A V E L L I
}

From the Institute of Neurosurgery and 2nd Clinic of Neurology, University of Pisa, Pisa, Italy

SUMMARY Blink reflexes were studied in 21 patients in coma after severe head injury. Our observations suggest that blink reflexes are a simple, objective, neurophysiological test to evaluate brainstem function. Correlations between these reflexes and the anatomoclinical stages of coma and the Glasgow coma scale have been established. Presence of the early R1 component shows the integrity of at least a part of the pontine structures. The appearance of the late R2 component is correlated with a better chance of recovery from coma.

Level of coma in severe head injury is assessed by evaluation of brainstem reflexes, motor reactivity, and eye movements, providing an anatomical interpretation of coma, defining various levels of lesion, viz. moderate (early) diencephalic or cortico-subcortical, severe (late) diencephalic, midbrain, pontine or ponto-medullary and medullary stages. Each stage indicates, in a rostral-caudal direction, the anatomical level reached by the brain damage, with inactivation of the structures located above it (Plum and Posner, 1972; Perez-Dominguez, 1974; Barge et al., 1977).

Other authors prefer to quantify some of the responses given by patients in coma to specific stimuli, such as pain or verbal stimuli, grading them in various levels or degrees of impairment of consciousness (Fischgold and Mathis, 1959; Bozza-Marrubini, 1964; Teasdale and Jennett, 1974).

Our aim was to gain further information on the anatomofunctional level of the lesion and on the prognosis of patients in post-traumatic coma, on the basis of blink reflexes studied by an electrophysiological method which has the advantage, as compared with clinical evaluation alone, of providing more easily quantifiable data and allowing serial comparisons.

Blink reflexes may be elicited by a variety of

This paper was presented in part at the Annual Meeting of the Italian Neurosurgical Society, Rome, 1977.

Address for reprint requests: Dr Roberto Buonaguidi, Institute of Neurosurgery, Spedali Riuniti "S. Chiara", Via Roma 5, 56100 Pisa, Italy.

Accepted 20 November 1978 stimuli: visual (flash), auditory (clap of hands), mechanical (glabellar tapping), or electrical. Electrical stimulation may be applied to various parts of the face, preferably to the areas innervated by the first and second branches of the trigeminal nerve.

Analysis of electromyographic recordings of blink reflexes elicited by electric stimulation of then supraorbital nerve reveals that they are composed as Kugelberg (1952) first proved, of an earlv․․ $\overrightarrow{0}$ component (R1) which is ipsilateral, quite stable 0 in its parameters, exhaustible only with difficulty; with brief latency $(10.6 \pm 2.5 \mathrm{~ms})$, and of a late

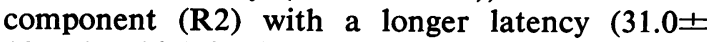
$10 \mathrm{~ms}$ ), which is bilateral, variable from subject to subject and, even in the same subject, tends to disappear with repetition of the stimulus.

Transmission of the early component seems to occur along a trigeminal-facial pontine, oligosynaptic arc (Shahani, 1970; Kimura, 1973). The late component, which corresponds to the visually observable blink, represents a multisynaptic reflex (Kugelberg, 1952; Shahani, 1970; Kimura, 1973) with neuronal circuits, apparently in the reticular substance of the brainstem (Kimura, 1971). Habituation of this reflex, with disappearance of $R 2$ on repetition of the stimulus, is a better known phenomenon which does not occur if the subject's intellectual capacities are damaged (Gregorič, 1973). Habituation of this reflex shortly after recovery from coma is a sign of good recovery of higher cerebral function (Gregorič, 1973; Serrats et al., 1976), indicating integrity of the cortical mechanisms of inhibition which act on brainstem structures (Messina and Quattrone, 1973; Gregorič, 1973). 
Patients and methods

Our study was performed on 21 patients in coma resulting from severe head injury. The ages of the patients ranged from 3 to 60 years, most being in the second and third decade. Of these 21 patients, eight underwent surgery for acute epidural or subdural haematoma just after admission to this Institute; others showed clinical signs of diffuse brain lesions with no neuroradiological signs of intracranial expansive processes. We considered a patient to be in coma and included him in the series, if for at least 48 hours he had not opened his eyes either spontaneously or after stimulation, if he did not obey commands, and if he did not give comprehensible verbal or motor responses.

Coma lasted from a minimum of 48 hours in one patient, up to three or four weeks. Five patients were in coma vigile (persistent vegetative state, according to Jennett and Plum's definition, 1972) one month after head injury and remained in such a condition for two to three months.

During the acute phase of coma the patients were kept in the neurosurgical intensive care unit.

The patients were assessed clinically by two methods. One was based on daily observation of the "anatomical level of coma," as proposed by Plum and Posner (1972), recording the state of consciousness, eye reflexes and movements, motor responses, behaviour of respiration, pupillary size and reflexes. The other was based on the Glasgow coma scale of Teasdale and Jennett (1974), recording the best responses obtained in three functions after verbal or painful stimulation: opening of eyes (4 degrees), motor responses (5 degrees), verbal responses (5 degrees).

Recording was made with a Medelec electromyograph, with three traces, of which two were used for recording and one for timing. Muscle potentials were derived with surface electrodes placed on the lower orbicular muscle of the eye on both sides.

Rectangular electric stimuli of $0.2 \mathrm{~ms}$ width and supramaximal intensity, were applied at the emergence of the supraorbital nerve. Habituation was assessed by stimulation with one shock every two seconds, for a total of 20 stimuli. The facial nerve was also stimulated directly to make sure that there were no lesions of its peripheral branches. The stimulus was applied to the area anterior to the mastoid process. The direct motor response had a brief latency $(3 \pm 1 \mathrm{~ms})$. Evaluation was limited to EMG recording of the blink reflexes performed during the first days after injury, when patients were in a condition of acute coma.

\section{Results}

In the two patients at the medullary anatomoclinical stage of coma (apnoea if respiratory support was withdrawn, muscular atony, fixed mydriasis, absence of oculovestibular reflexes) blink reflexes (EMG) proved to be absent. The coma was fatal (Table 1).

Five cases were found to be at the pontinemedullary anatomoclinical coma stage (superficial and ataxic respiration, muscular atony or flexor hypertonus of lower limbs, bilateral Babinski responses, rare decerebrate rigidity, absence of oculovestibular reflexes, rare ocular bobbing). In two of these patients blink reflexes were absent. In another two an $\mathrm{R} 1$ response of minimal amplitude and with increased latency $(13.6 \mathrm{~ms}$ and $15.3 \mathrm{~ms}$ respectively) could be observed on one side only. In the fifth patient both $\mathrm{R} 1$ responses and a left direct $\mathrm{R} 2$ of minimal amplitude were present. All five patients died.

Of the four patients at the midbrain anatomoclinical stage (central hyperventilation, hypertonus of the four limbs, bilateral Babinski responses, incomplete or disconjugated oculovestibular reflexes) one had on the right an R1 of minimal amplitude, with normal latency; two had both $\mathrm{R} 1$ responses of minimal amplitude and with increased latency $(15.0$ and $15.7 \mathrm{~ms}$ in one case and 15.0 and $13.5 \mathrm{~ms}$ in the other). The direct and consensual $\mathrm{R} 2$ responses were absent. In the fourth patient, $\mathrm{R} 1$ was present on both sides and direct R2 on the right; all responses were of minimal amplitude. One month after injury, the clinical condition of one patient was of the persistent vegetative type, while the other three were seriously disabled.

The clinical outcome of injury was assessed according to the classification of Jennett and Bond (1975). In five cases of severe diencephalic coma (Cheyne-Stokes breathing, motor agitation, decorticate rigidity, presence of oculovestibular reflexes though often only in the tonic phase), $\mathbf{R} 1$ responses with normal latency (in a single case it was increased on one side) were always present on both sides; in two cases a direct R2 of minimal amplitude was observed on one side only. One month after injury, four patients were in a persistent vegetative state and one was seriously disabled.

Blink reflexes were all present, with normal latencies and amplitudes, in the five patients with moderate diencephalic coma (drowsy state, withdrawal from painful stimuli, sometimes presence of moaning, presence of oculovestibular reflexes). Blepharospasm (a prolonged contraction of the 
Table 1 Correlation between clinical level of coma and blink reflexes

\begin{tabular}{|c|c|c|c|c|c|c|c|}
\hline \multirow{2}{*}{$\begin{array}{l}\text { Anatomoclinical level of coma } \\
\text { (Plum and Posner, 1972) }\end{array}$} & \multirow{2}{*}{$\begin{array}{l}\text { Glasgow } \\
\text { coma scale } \\
\text { score }\end{array}$} & \multirow[t]{2}{*}{ Case } & \multicolumn{4}{|c|}{ Blink reflexes } & \multirow{2}{*}{$\begin{array}{l}\text { Outcome after a } \\
\text { month }\end{array}$} \\
\hline & & & Side & $R 1$ & $\begin{array}{l}\text { R2 } \\
\text { direct }\end{array}$ & $\begin{array}{l}\text { R2 } \\
\text { consensual }\end{array}$ & \\
\hline Medullary & $\begin{array}{l}3 \\
3\end{array}$ & $\begin{array}{l}1420 \\
2392\end{array}$ & $\begin{array}{l}\mathbf{R} \\
\mathbf{L} \\
\mathbf{R} \\
\mathbf{L}\end{array}$ & $\begin{array}{l}0 \\
0 \\
0 \\
0\end{array}$ & $\begin{array}{l}0 \\
0 \\
0 \\
0\end{array}$ & $\begin{array}{l}0 \\
0 \\
0 \\
0\end{array}$ & $\begin{array}{l}\text { Dead } \\
\text { Dead }\end{array}$ \\
\hline Pontine-medullary & $\begin{array}{l}4 \\
3 \\
4 \\
4 \\
5\end{array}$ & $\begin{array}{l}1557 \\
1801 \\
1827 \\
2767 \\
2823\end{array}$ & $\begin{array}{l}\mathbf{R} \\
\mathbf{L} \\
\mathbf{R} \\
\mathbf{L} \\
\mathbf{R} \\
\mathbf{L} \\
\mathbf{R} \\
\mathbf{L} \\
\mathbf{R} \\
\mathbf{L}\end{array}$ & $\begin{array}{l}0 \\
0 \\
+ \\
0 \\
0 \\
0 \\
+ \\
0 \\
+ \\
+ \\
+\end{array}$ & $\begin{array}{l}0 \\
0 \\
0 \\
0 \\
0 \\
0 \\
0 \\
0 \\
0 \\
+\end{array}$ & $\begin{array}{l}0 \\
0 \\
0 \\
0 \\
0 \\
0 \\
0 \\
0 \\
0 \\
0\end{array}$ & $\begin{array}{l}\text { Dead } \\
\text { Dead } \\
\text { Dead } \\
\text { Dead } \\
\text { Dead }\end{array}$ \\
\hline Midbrain & $\begin{array}{l}4 \\
5 \\
5 \\
5\end{array}$ & $\begin{array}{l}1095 \\
2961 \\
3065 \\
3092\end{array}$ & $\begin{array}{l}\mathbf{R} \\
\mathbf{L} \\
\mathbf{R} \\
\mathbf{L} \\
\mathbf{R} \\
\mathbf{L} \\
\mathbf{R} \\
\mathbf{L}\end{array}$ & $\begin{array}{l}+ \\
+ \\
+ \\
0 \\
+ \\
+ \\
+ \\
+\end{array}$ & $\begin{array}{l}+ \\
0 \\
0 \\
0 \\
0 \\
0 \\
0 \\
0\end{array}$ & $\begin{array}{l}0 \\
0 \\
0 \\
0 \\
0 \\
0 \\
0 \\
0\end{array}$ & $\begin{array}{l}\text { Vegetative state } \\
\text { Severe disability } \\
\text { Severe disability } \\
\text { Severe disability }\end{array}$ \\
\hline Severe (late) diencephalic & $\begin{array}{l}5 \\
5 \\
5 \\
5 \\
5\end{array}$ & $\begin{array}{l}2777 \\
2824 \\
2275 \\
2311 \\
1135\end{array}$ & $\begin{array}{l}\mathbf{R} \\
\mathbf{L} \\
\mathbf{R} \\
\mathbf{L} \\
\mathbf{R} \\
\mathbf{L} \\
\mathbf{R} \\
\mathbf{L} \\
\mathbf{R} \\
\mathbf{L}\end{array}$ & $\begin{array}{l}+ \\
+ \\
+ \\
+ \\
+ \\
+ \\
+ \\
+ \\
+ \\
+\end{array}$ & $\begin{array}{l}0 \\
+ \\
0 \\
0 \\
0 \\
0 \\
0 \\
0 \\
+ \\
0\end{array}$ & $\begin{array}{l}0 \\
0 \\
0 \\
0 \\
0 \\
0 \\
0 \\
0 \\
0 \\
0\end{array}$ & $\begin{array}{l}\text { Vegetative state } \\
\text { Vegetative state } \\
\text { Vegetative state } \\
\text { Vegetative state } \\
\text { Severe disability }\end{array}$ \\
\hline Moderate (early) diencephalic & $\begin{array}{r}10 \\
7 \\
9 \\
8 \\
8\end{array}$ & $\begin{array}{l}3029 \\
2496 \\
2388 \\
2561 \\
1794\end{array}$ & $\begin{array}{l}\mathbf{R} \\
\mathbf{L} \\
\mathbf{R} \\
\mathbf{L} \\
\mathbf{R} \\
\mathbf{L} \\
\mathbf{R} \\
\mathbf{L} \\
\mathbf{R} \\
\mathbf{L}\end{array}$ & $\begin{array}{l}+ \\
+ \\
+ \\
+ \\
+ \\
+ \\
+ \\
+ \\
+ \\
+\end{array}$ & $\begin{array}{l}+ \\
+ \\
+ \\
+ \\
\mathbf{B} \\
\mathbf{B} \\
+ \\
\mathbf{B} \\
\mathbf{B} \\
+\end{array}$ & $\begin{array}{l}+ \\
+ \\
+ \\
+ \\
\mathbf{B} \\
\mathbf{B} \\
+ \\
\mathbf{B} \\
\mathbf{B} \\
+\end{array}$ & $\begin{array}{l}\text { Severe disability } \\
\text { Moderate disability } \\
\text { Moderate disability } \\
\text { Dead (pulmonary } \\
\text { embolism) } \\
\text { Good recovery }\end{array}$ \\
\hline
\end{tabular}

$0=$ absent, $+=$ present, $B=$ blepharospasm.

orbiculares oculorum muscles) which indicates release of a primitive reflex which is usually inhibited by cortical structures (Fisher, 1963) was noted in three of them. Of these patients, one died of massive pulmonary embolism (badly fractured limbs had kept him immobilised for a long time) after having recovered consciousness; another was severely disabled one month later. Two were moderately disabled and another made a good recovery.

If the score according to the Glasgow coma scale is compared with the blink reflexes of our coma patients, it may be noted that for a score of 3 or 4 , reflexes were absent or only $\mathrm{R} 1$ was present on one side (in a single patient we found $\mathrm{R} 1$ present bilaterally along with a direct $\mathrm{R} 2$ ).

For a score of 5, 6, or 7, R1 was found to be present almost always bilaterally. In three patients R2 was also present. All reflexes were found to be present for a score of 8 or more (Table 2).

One month after the first recording all blink reflexes could be observed in the five patients who were in a persistent vegetative state, and three had blepharospasm (Table 3 ). Three months after injury, habituation of the reflex was still absent in all the patients who had recovered consciousness; habituation could be observed six to eight months after injury in patients who had made a good recovery.

\section{Discussion}

Our study, though limited to 21 patients in coma resulting from severe head injury, reveals a 
Table 2 Correlation between score on Glasgow coma scale and blink reflexes

\begin{tabular}{|c|c|c|c|c|c|c|}
\hline \multirow{2}{*}{$\begin{array}{l}\text { Score } \\
\text { on } \\
\text { Glasgow } \\
\text { coma } \\
\text { scale }\end{array}$} & \multicolumn{6}{|c|}{ Blink reflexes } \\
\hline & Absent & $\begin{array}{l}\text { R1 one } \\
\text { side } \\
\text { only }\end{array}$ & $\begin{array}{l}R I \\
\text { both } \\
\text { sides }\end{array}$ & $\begin{array}{l}R 1, R 2 \\
\text { direct }\end{array}$ & $\begin{array}{l}R 1, R 2 \\
\text { both } \\
\text { sides }\end{array}$ & Blepharospasm \\
\hline $3-4$ & 4 & 2 & & 1 & & \\
\hline $5-6-7$ & & 1 & 5 & 2 & 1 & \\
\hline 8 & & & & 1 & 1 & 3 \\
\hline
\end{tabular}

Table 3 Correlation between clinical level of coma and blink reflexes

\begin{tabular}{|c|c|c|c|c|c|c|}
\hline \multirow{2}{*}{$\begin{array}{l}\text { Anatomo- } \\
\text { clinical } \\
\text { level of coma } \\
\text { (Plum and } \\
\text { Posner, } \\
\text { 1972) }\end{array}$} & \multicolumn{6}{|c|}{ Blink reflexes } \\
\hline & Absent & $\begin{array}{l}\text { RI one } \\
\text { side } \\
\text { only }\end{array}$ & $\begin{array}{l}\text { RI } \\
\text { both } \\
\text { sides }\end{array}$ & $\begin{array}{l}R 1, R 2 \\
\text { direct }\end{array}$ & $\begin{array}{l}R 1, R 2 \\
\text { both } \\
\text { sides }\end{array}$ & Blepharospasm \\
\hline Medullary & 2 & & & & & \\
\hline $\begin{array}{l}\text { Pontine- } \\
\text { medullary }\end{array}$ & 2 & 2 & & 1 & & \\
\hline Midbrain & & 1 & 2 & 1 & & \\
\hline $\begin{array}{l}\text { Severe (late) } \\
\text { diencephalic }\end{array}$ & & & 3 & 2 & & \\
\hline $\begin{array}{l}\text { Moderate } \\
\text { (early) } \\
\text { diencephalic }\end{array}$ & & & & & 2 & 3 \\
\hline $\begin{array}{l}\text { Persistent } \\
\text { vegetative } \\
\text { state } \\
\text { (five subjects } \\
\text { a month } \\
\text { after head } \\
\text { injury) }\end{array}$ & & & & & 2 & 3 \\
\hline
\end{tabular}

relationship between coma stages as established by the anatomoclinical method (Table 3 ) or by the grading method and blink reflexes obtained with an electrophysiological technique (Table 2).

Absence of all blink reflexes was observed when clinical signs of anatomical or functional disorder of the medullary or pontine-medullary region was found. Such patients normally survive for only a few days with the aid of mechanical respirators. Along with other clinical and instrumental investigations, the absence of blink reflexes may be considered as an additional criterion in the diagnosis of brain death (Mehta and Seshia, 1976).

As in our cases, it must be confirmed that response to direct stimulation of facial nerve is present. In two of the patients with abnormal function at a pontine-medullary level, the R1 response was present on one side only, with increased latency and minimal amplitude. A discrepancy was found in a single patient between the clinical data indicating a pontine-medullary lesion and the EMG finding with both $\mathrm{R} 1$ and a direct R2 responses present, even though of minimal amplitude. This was a sign of functional integrity of the pontine tract. In fact, the direct $\mathrm{R} 2$ responses are found to be present when most of the pontine structures have been preserved (Kimura, 1970, 1971, 1973; Lyon et al., 1972; Serrats et al., 1976; Rossi and Buonaguidi, 1977).

Patients at a midbrain or severe diencephalic stage of coma have both $\mathrm{R} 1$ responses, and in some cases a direct $\mathrm{R} 2$ response starts to appear. We believe that the presence of a direct $R 2$ response, even though unilateral, could be an important datum in the study of evolution of coma. The appearance of the $\mathrm{R} 2$ response is very probably strongly correlated with the anatomoclinical mesodiencephalic level of coma, generally considered as being the limit above which there is a high percentage of favourable prognosis (Barge et al., 1978).

Finally, direct and consensual R2 responses are present in patients at a moderate diencephalic stage of coma and in patients in the persistent vegetative state.

Data on brainstem function, obtained by a study of blink reflexes, correlate well with the clinical evaluation of stages of coma. Neurophysiological methods have the advantage of being more quantifiable. Blink reflexes also allow evaluation of some phenomena such as blepharospasm and habituation which are overlooked in clinical examination. The phenomena are very useful in the evaluation of the influence of the higher nervous system on brainstem function.

We would like to thank Dr Nadia Simonini for her assistance in the preparation of the manuscript. This work was supported in part by the CNR.

\section{References}

Barge, M., Ohanessian, J., Benabid, A. L., and Chirossel, J. P. (1977). Valeur diagnostique et prognostique des réflexes du tronc cérébral dans les comas post-traumatique graves. Neurochirurgie, 23, 227-238.

Barge, M., Ohanessian, J., Garrel, S., Benabid, A. L., and Chirossel, J. P. (1978). Le stade mésodiencéphalique des traumatismes craniens graves. Neurochirurgie, 24, 33-36.

Bozza-Marrubini, M. L. (1964). Resuscitation treatment of different degrees of unconsciousness. Acta Neurochirurgica, 12, 352-365.

Fischgold, H., and Mathis, P. (1959). Obnubilations, comas et stupeurs. Electroencephalography and Clinical Neurophysiology, Supplement 2. Masson, Paris. 
Fisher, C. M. (1963). Reflex blepharospasm. Neurology (Minneapolis), 13, 77-78.

Gregorič, M. (1973). Habituation of blink reflex. Role of selective attention. In New Developments in Electromyography and Clinical Neurophysiology, vol. 3, pp. 673-677. Edited by J. E. Desmedt. Karger: Basel.

Jennett, B., and Bond, M. (1975). Assessment of outcome after severe brain damage. Lancet, 1, 480.

Jennett, B., and Plum, F. (1972). Persistent vegetative state after brain damage. Lancet, 1, 734-737.

Kimura, J. (1970). Alteration of the orbicularis oculi reflex by pontine lesions. Archives of Neurology (Chicago), 22, 156-161.

Kimura, J. (1971). Electrodiagnostic study of brainstem. Stroke, 2, 576-586.

Kimura, J. (1973). The blink reflex as a test for brainstem and higher central nervous system function. In New Developments in Electromyography and Clinical Neurophysiology, vol. 3, pp. 682-691. Edited by J. E. Desmedt. Karger: Basel.

Kugelberg, E. (1952). Facial reflexes. Brain, 76, 385396.

Lyon, L. W., Kimura, J., and McCormick, W. F. (1972). Orbicularis oculi reflex in coma: clinical, electrophysiological and pathological correlations.
Journal of Neurology, Neurosurgery, and Psychiatry, 35, 582-588.

Mehta, A. J., and Seshia, S. S. (1976). Orbicularis of oculi reflexes in brain death. Journal of Neurology, Neurosurgery, and Psychiatry, 39, 784-787.

Messina, C., and Quattrone, A. (1973). Comportamento dei riflessi trigemino-facciali in soggetti con $\triangle$ lesioni emisferiche. Rivista di Neurologia, 43, 379392.

Perez-Dominguez, E. (1974). Les réflexes du tronc. cérébral. Leur valeur dans l'étude des comas. Thèse, $\overrightarrow{\mathcal{B}}$ Université du Montpellier.

Plum, F., and Posner, J. (1972). Diagnosis of Stupor and Coma. Davis: Philadelphia.

Rossi, B., and Buonaguidi, R. (1977). The trigeminofacial reflexes in coma. Acta Neurochirurgica, 38, $\stackrel{\varnothing}{\varrho}$ 137.

Serrats, A. F., Parker, S. A., and Merino-Canas, A. (1976). The blink reflex in coma and after recovery $\vec{\circ}$ from coma. Acta Neurochirurgica, 34, 79-97.

Shahani, B. (1970). The human blink reflex. Journal $\vec{\omega}$ of Neurology, Neurosurgery, and Psychiatry, 33, 792-800.

Teasdale, G., and Jennett, B. (1974). Assessment of coma and impaired consciousness. A practical scale. N Lancet, 2, 81-84. 